\title{
The legacy of the Philadelphia chromosome
}

\author{
Gary A. Koretzky \\ Abramson Family Cancer Research Institute, University of Pennsylvania Cancer Center, and Department of Pathology and Laboratory Medicine, \\ Rheumatology Division, Department of Medicine, University of Pennsylvania School of Medicine, Philadelphia, Pennsylvania, USA.
}

\begin{abstract}
The discovery of the Philadelphia chromosome as a hallmark of chronic myelogenous leukemia in 1960 by Peter Nowell provided evidence for a genetic link to cancer. As with most seminal scientific observations, the description of the Philadelphia chromosome posed many more questions than were answered. This Review series includes contributions from individuals who performed critical experiments addressing some of the most important of these questions, reflecting the nearly 50 years of work inspired by Nowell's initial finding. The legacy of the Philadelphia chromosome now serves as a paradigm for how basic science discoveries can lead to effective new approaches for the treatment of human disease.
\end{abstract}

In 1960, Peter C. Nowell (Figure 1), then a junior faculty member at the University of Pennsylvania School of Medicine, together with a graduate student, David Hungerford, described an unusual small chromosome present in leukocytes from patients with chronic myelogenous leukemia (CML) (1). This abnormality, designated the Philadelphia chromosome after the city in which it was discovered (2), was not found in normal leukocytes but was present in the malignant cells of CML patients. Although a number of previous studies had shown chromosomal abnormalities in human cancer, the Philadelphia chromosome was the first documentation of a bona fide genetic signature of malignancy, and this discovery led Nowell to hypothesize that this genetic alteration might somehow provide a growth advantage to the abnormal cells.

Nowell's description of the Philadelphia chromosome ushered in a new era in cancer research. As with nearly all paradigm-shifting experiments, the initial report of the Philadelphia chromosome and its apparent relationship to cancer raised many more questions than it answered. Among the most important of these questions was whether the Philadelphia chromosome represented a genetic change that was the cause or the consequence of CML. If causal, what was it about the chromosomal abnormality that led to disease, and if an abnormal gene product was the culprit, could knowledge about this gene product lead to new therapeutic interventions? Importantly, it was also critical to learn whether the genetic instability associated with CML was generalizable to other malignancies or if it represented a unique situation for an important but still relatively uncommon human cancer.

The last 47 years have seen an explosion of knowledge as answers to each of these and other related questions have been sought. As cytogenetic techniques improved, the abnormal chromosome visualized by Hungerford and Nowell was determined to be the result of a reciprocal translocation between the long arms of chromosomes 9 and 22 (3). Later work revealed that this translocation resulted in a fusion protein that was expressed in the malignant cells (4-8). This work spurred intense evaluation of other cancers to determine whether other cytogenetic changes could be linked to malignancies, thus generalizing this

Nonstandard abbreviations used: $\mathrm{Abl}, \mathrm{v}-\mathrm{Abl}$ Abelson murine leukemia viral oncogene homolog; BCR, breakpoint cluster region; CML, chronic myelogenous leukemia. Conflict of interest: The author has declared that no conflict of interest exists. Citation for this article: J. Clin. Invest. 117:2030-2032 (2007). doi:10.1172/JCI33032. new paradigm. As the readers of this series will appreciate, the results of these studies have had far reaching implications in our understanding of the genetic basis of cancer, as chromosomal abnormalities are now known to be signatures of malignancies in multiple tissues.

The potential significance of the fusion protein breakpoint cluster region-v-Abl Abelson murine leukemia viral oncogene homo$\log (\mathrm{BCR}-\mathrm{Abl})$, produced as the gene product of the $\mathrm{t}(9 ; 22)$ translocation, became apparent as parallel studies in other laboratories identified and began to characterize protein tyrosine kinases. With the discovery of this class of enzymes, seminal experiments showed that they were absolutely critical control points in cellular growth and differentiation and that dysregulation of these enzymes could lead to abnormal, i.e., malignant, cell growth (9-15). The link to CML became clear, as sequence homology and enzymatic assays showed that the $\mathrm{Abl}$ component itself was a protein tyrosine kinase (16) and that the fusion protein had lost its appropriate regulation (17). Subsequently, a series of important studies using animal models demonstrated that BCR-Abl is oncogenic (18-21) and is the cause, not the result, of CML.

With this information in hand, the stage was set for attempts at rational drug design. Until then, the standard therapy for CML was similar to treatment for other malignancies: administration of cytotoxic agents in the hopes that malignant cells would be killed disproportionately and that the killing would be robust and selective enough so that the host could eventually mount an effective antitumor response. Unfortunately, this positive outcome was rarely the case, and without specific therapy against the malignant cells, cures were rarely achieved. Identifying the gene product causal for disease, however, encouraged investigators to search for agents that would specifically interfere with the function of the BCR-Abl fusion protein. This search eventually led to the identification of imatinib mesylate (Gleevec) as a BCR-Abl inhibitor (22-24) and has dramatically affected the quality of life of patients suffering from CML (25-27). Thus, the story of the Philadelphia chromosome stands as a model for how a clinical observation can be followed by rigorous basic science using novel approaches, leading to new hypotheses that can be translated into clinical practice.

In September 2006, the Department of Pathology and Laboratory Medicine and the Abramson Cancer Center at the University of Pennsylvania School of Medicine sponsored a symposium to honor Peter Nowell's contributions after 50 years on its faculty. We were able to bring together some of the individuals who made 

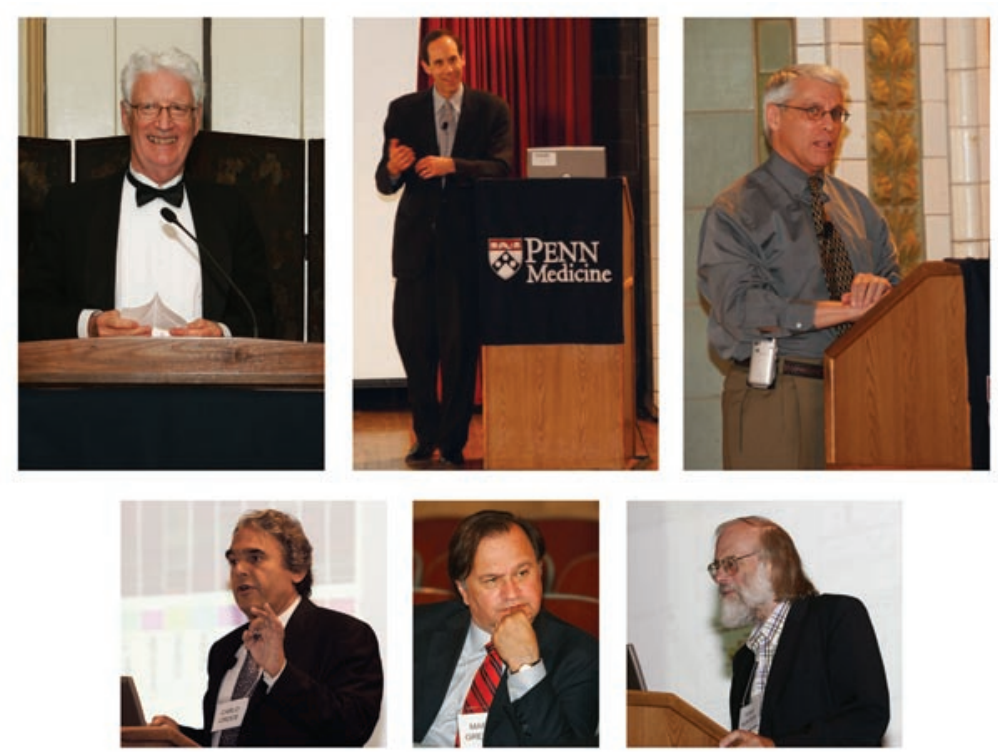

Figure 1

Peter Nowell, discoverer of the Philadelphia chromosome, at the September 2006 symposium in his honor, along with Brian Druker, Owen Witte (top row), Carlo Croce, Mark Greene, and Tony Hunter (bottom row).

seminal discoveries directly related to or inspired by Nowell's work (Figure 1). This Review series is a collection of articles by those who presented at the symposium.

The first article in the series is authored by Nowell himself (28). In his Review, Nowell presents a historical perspective describing what was known in 1960 about cancer and genetics and what the technical issues were that limited the ability of investigators to pursue their work to the next level of rigor. This Review reminds the reader of the progress that has been made over the past several decades to overcome technical barriers, as we are now able to conduct definitive studies to investigate the molecular underpinnings of malignancies. Importantly, Nowell's perspective emphasizes how the work of others influenced his thinking and how the efforts of multiple investigators from around the world collectively led to major new discoveries. This review sets the stage for the other five articles in the series.

Tony Hunter of the Salk Institute for Biological Studies was invited to participate in the symposium because of his seminal work investigating the biology of protein tyrosine kinases and how dysregulation of these enzymes may contribute to malignancy. Like Nowell, Hunter provides a broad historical perspective on how our understanding of tyrosine kinases unfolded, emphasizing how studies can catalyze new discoveries in unexpected ways (29). Hunter provides a detailed chronology of the experiments performed after the identification of the Philadelphia chromosome that led to our understanding of the molecular basis for CML and ultimately to the development of an effective therapy.

Owen Witte from the University of California, Los Angeles, working with David Baltimore, performed some of the most critical studies demonstrating the tyrosine kinase activity of c-Abl, the dysregulation of kinase function when $\mathrm{Abl}$ is fused to BCR, and the transforming capability of the fusion protein. In their Review, Devon Lawson and Witte provide the conceptual link from the early discovery of the Philadelphia chromosome and genetic alterations that are hallmarks of cancer to the current notion of cancer stem cells (30). Investigation of these important cells, in particular their role in prostate cancer, has become a major focus, and the most current studies from the field are highlighted in the Review.

The next article in our series is provided by Mark Greene and colleagues (31). Greene, a colleague of Nowell's at the University of Pennsylvania, was recruited by Nowell to join the faculty at Penn, in large part because of the Greene group's interest in protein tyrosine kinases (in this case, members of the EGFR family) as they relate to cancer (32-34). In their Review, Greene and colleagues describe the history of the discovery of the role of these kinases in malignancy, emphasizing the molecular basis of how mutant kinases exhibit dysregulated function. They then describe the development of novel therapeutics directed against EGFR family members, providing another exciting example of how basic discovery of the molecular pathogenesis of disease is leading to specific interventions.

The fifth Review for our series is contributed by George Calin and Carlo Croce, who is currently at The Ohio State University (35). Before his move to Columbus, Croce spent many years in Philadelphia and was an active collaborator with Nowell on a number of intriguing projects. The Nowell/Croce collaboration led to several important discoveries examining other chromosomal alterations in malignancies, in particular the finding that the proto-oncogene Myc was transcriptionally activated due to a translocation associated with Burkitt lymphoma (36-38). In their Review, Croce and Calin describe much more recent work, examining the possibility that genes encoding microRNAs may function as cancer susceptibility loci.

The final Review in the series brings the basic discoveries surrounding the Philadelphia chromosome back to the bedside (39). This Review, contributed by Brian Druker and Daniel Sherbenou from the Oregon Health Sciences University, highlights the development of imatinib. Druker, who has contributed more than any other investigator to bringing this agent from the laboratory to the patient, describes the chronology of its use. Although this drug has revolutionized CML therapy (as well as treatment of other malignancies), finding new treatments for CML relapse due to the development of drug resistance is the next challenge. Druker and Sherbenou describe strategies that are being taken as the next generation of inhibitors is being considered.

The individuals who attended the symposium at the University of Pennsylvania last September were treated to a special day that brought together the authors of these reviews, along with Janet Rowley from the University of Chicago [the scientist who defined the Philadelphia chromosome as a $t(9 ; 22)$ reciprocal translocation], each of whom delivered an engaging seminar. We hope that the articles compiled in this review series will enable the readers of the JCI to capture some of the excitement of that day.

Address correspondence to: Gary A. Koretzky, Abramson Family Cancer Research Institute, 415 BRB II/III, 421 Curie Blvd., Philadelphia, Pennsylvania 19104, USA. Phone: (215) 746-5522; Fax: (215) 746-5525; E-mail: Koretzky@mail.med.upenn.edu. 
1. Nowell, P., and Hungerford, D. 1960. A minute chromosome in human chronic granulocytic leukemia. Science. 132:1497.

2. Nowell, P.C., and Hungerford, D.A. 1960. Chromosome studies on normal and leukemic human leukocytes. J. Natl. Cancer Inst. 25:85-109.

3. Rowley, J.D. 1973. Letter: A new consistent chromosomal abnormality in chronic myelogenous leukaemia identified by quinacrine fluorescence and Giemsa staining. Nature. 243:290-293.

4. de Klein, A., et al. 1982. A cellular oncogene is translocated to the Philadelphia chromosome in chronic myelocytic leukaemia. Nature. 300:765-767.

5. Groffen, J., et al. 1984. Philadelphia chromosomal breakpoints are clustered within a limited region, bcr, on chromosome 22. Cell. 36:93-99.

6. Heisterkamp, N., et al. 1983. Localization of the c-ab1 oncogene adjacent to a translocation break point in chronic myelocytic leukaemia. Nature. 306:239-242.

7. Shtivelman, E., Lifshitz, B., Gale, R.P., and Canaani, E. 1985. Fused transcript of abl and bcr genes in chronic myelogenous leukaemia. Nature. 315:550-554.

8. Stam, K., et al. 1985. Evidence of a new chimeric $\mathrm{bcr} / \mathrm{c}$-abl mRNA in patients with chronic myelocytic leukemia and the Philadelphia chromosome. N. Engl. J. Med. 313:1429-1433.

9. Brugge, J.S., and Erikson, R.L. 1977. Identification of a transformation-specific antigen induced by an avian sarcoma virus. Nature. 269:346-348.

10. Collett, M.S., Brugge, J.S., and Erikson, R.L. 1978. Characterization of a normal avian cell protein related to the avian sarcoma virus transforming gene product. Cell. 15:1363-1369.

11. Levinson, A.D., Oppermann, H., Levintow, L., Varmus, H.E., and Bishop, J.M. 1978. Evidence that the transforming gene of avian sarcoma virus encodes a protein kinase associated with a phosphoprotein. Cell. 15:561-572.

12. Collett, M.S., and Erikson, R.L. 1978. Protein kinase activity associated with the avian sarcoma virus src gene product. Proc. Natl. Acad. Sci. U. S. A. 75:2021-2024.

13. Eckhart, W., Hutchinson, M.A., and Hunter, T. 1979. An activity phosphorylating tyrosine in polyoma $T$ antigen immunoprecipitates. Cell. 18:925-933.

14. Hunter, T., and Sefton, B.M. 1980. Transforming gene product of Rous sarcoma virus phosphorylates tyrosine. Proc. Natl. Acad. Sci. U. S. A. 77:1311-1315.

15. Ushiro, H., and Cohen, S. 1980. Identification of phosphotyrosine as a product of epidermal growth factor-activated protein kinase in A-431 cell membranes. J. Biol. Chem. 255:8363-8365.

16. Witte, O.N., Dasgupta, A., and Baltimore, D. 1980. Abelson murine leukaemia virus protein is phosphorylated in vitro to form phosphotyrosine. Nature. 283:826-831.

17. Konopka, J.B., Watanabe, S.M., and Witte, O.N. 1984. An alteration of the human c-abl protein in K562 leukemia cells unmasks associated tyrosine kinase activity. Cell. 37:1035-1042.

18. Daley, G.Q., Van Etten, R.A., and Baltimore, D. 1990. Induction of chronic myelogenous leukemia in mice by the P210bcr/abl gene of the Philadelphia chromosome. Science. 247:824-830.

19. Elefanty, A.G., Hariharan, I.K., and Cory, S. 1990. bcr-abl, the hallmark of chronic myeloid leukaemia in man, induces multiple haemopoietic neoplasms in mice. EMBO J. 9:1069-1078.

20. Heisterkamp, N., et al. 1990. Acute leukaemia in bcr/abl transgenic mice. Nature. 344:251-253.

21. Kelliher, M.A., McLaughlin, J., Witte, O.N., and Rosenberg, N. 1990. Induction of a chronic myelogenous leukemia-like syndrome in mice with v-abl and BCR/ABL. Proc. Natl. Acad. Sci. U. S. A. 87:6649-6653.

22. Buchdunger, E., et al. 1996. Inhibition of the Abl protein-tyrosine kinase in vitro and in vivo by a 2-phenylaminopyrimidine derivative. Cancer Res. 56:100-104.

23. Druker, B.J., et al. 1996. Effects of a selective inhibitor of the Abl tyrosine kinase on the growth of $\mathrm{Bcr}$ Abl positive cells. Nat. Med. 2:561-566.

24. Carroll, M., et al. 1997. CGP 57148, a tyrosine kinase inhibitor, inhibits the growth of cells expressing BCR-ABL, TEL-ABL, and TEL-PDGFR fusion proteins. Blood. 90:4947-4952.

25. Druker, B.J., et al. 2001. Activity of a specific inhibitor of the BCR-ABL tyrosine kinase in the blast crisis of chronic myeloid leukemia and acute lymphoblastic leukemia with the Philadelphia chromosome. N. Engl. J. Med. 344:1038-1042.

26. Druker, B.J., et al. 2001. Efficacy and safety of a specific inhibitor of the BCR-ABL tyrosine kinase in chronic myeloid leukemia. N. Engl. J. Med. 344:1031-1037.

27. Sawyers, C.L., et al. 2002. Imatinib induces hema- tologic and cytogenetic responses in patients with chronic myelogenous leukemia in myeloid blast crisis: results of a phase II study. Blood. 99:3530-3539.

28. Nowell, P.C. 2007. Discovery of the Philadelphia chromosome: a personal perspective. J. Clin. Invest. 117:2033-2035. doi:10.1172/JCI31771.

29. Hunter, T. 2007. Treatment for chronic myelogenous leukemia: the long road to imatinib. J. Clin. Invest. 117:2036-2043. doi:10.1172/JCI31691.

30. Lawson, D.A., and Witte, O.N. 2007. Stem cells in prostate cancer initiation and progression. J. Clin. Invest. 117:2044-2050. doi:10.1172/JCI32810.

31. Zhang, H., et al. 2007. ErbB receptors: from oncogenes to targeted cancer therapies. J. Clin. Invest. 117:2051-2058. doi:10.1172/JCI32278.

32. Drebin, J.A., Link, V.C., Weinberg, R.A., and Greene, M.I. 1986. Inhibition of tumor growth by a monoclonal antibody reactive with an oncogeneencoded tumor antigen. Proc. Natl. Acad. Sci. U.S. A. 83:9129-9133.

33. Kokai, Y., et al. 1988. Phosphorylation process induced by epidermal growth factor alters the oncogenic and cellular neu (NGL) gene products. Proc. Natl. Acad. Sci. U. S. A. 85:5389-5393.

34. Wada, T., Qian, X.L., and Greene, M.I. 1990. Intermolecular association of the $\mathrm{p} 185$ neu protein and EGF receptor modulates EGF receptor function. Cell. 61:1339-1347.

35. Calin, G.A., and Croce, C.M. 2007. Chromosomal rearrangements and microRNAs: a new cancer link with clinical implications. J. Clin. Invest. 117:2059-2066. doi:10.1172/JCI32577.

36. Croce, C.M., et al. 1983. Transcriptional activation of an unrearranged and untranslocated c-myc oncogene by translocation of a C lambda locus in Burkitt. Proc. Natl. Acad. Sci. U. S. A. 80:6922-6926.

37. Erikson, J., et al. 1983. Translocation of an immunoglobulin kappa locus to a region 3 ' of an unrearranged c-myc oncogene enhances c-myc transcription. Proc. Natl. Acad. Sci. U. S. A. 80:7581-7585.

38. Nowell, P., et al. 1983. Association of amplified oncogene c-myc with an abnormally banded chromosome 8 in a human leukaemia cell line. Nature. 306:494-497.

39. Sherbenou, D.W., and Druker, B.J. 2007. Applying the discovery of the Philadelphia chromosome. J. Clin. Invest. 117:2067-2074. doi:10.1172/ JCI31988. 